\title{
Ophthalmic lesions due to pine-flower pollen
}

\author{
JOHN SPERO KINNAS \\ Corinth, Greece
}

It is well known that allergic manifestations in the eye may be caused by shrubs, grasses, and the seeds and pollen of flowers (Duke-Elder, i 965 ).

The following observations refer to the pollen of the male flowers of the pine tree. This pollen reaches maturity and is scattered around between mid-March and mid-April, and during this time the eyes of persons in the neighbourhood of the trees may be affected. We have observed nine such cases, two of which are reported in detail below:

\section{DIREGT CONTACT}

Case I, a girl aged 16, working as a goatherd. Her right eye came into direct contact with pollen as a result of pollen-sacs or pine-twigs carrying male flowers striking her face. The subjective symptoms were immediate and intense, causing her to rub the affected eye violently, and when she was seen 14 hours later (Fig. I) the pollen and pollen-magma were found to have settled as a more or less dense coating around and in the eye. There was a pronounced diffuse oedema, especially of the eye lids.

(a)

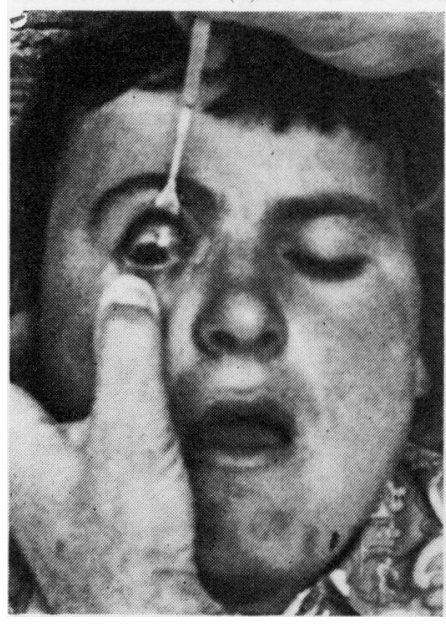

(b)

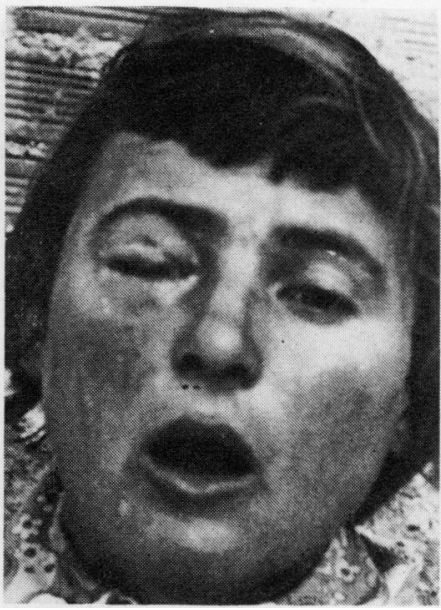

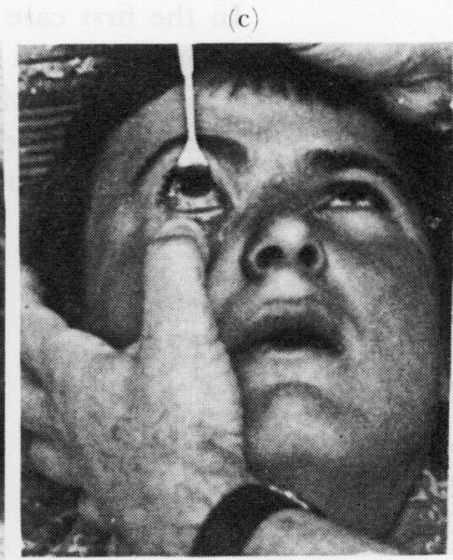

FIGURE Case I, showing the results of direct contact with pollen from male pine-tree flowers

The bulbar conjunctiva in particular showed scattered superficial erosions in the epithelial layer, a marked vascular dilatation, and in places slight ecchymosis.

Biomicroscopy revealed the presence of pale, transparent, papillae of pinhead size, with catarrh and infiltration into the adjacent areas. Some of these papillae showed an epithelial erosion at the apex, mostly with some light-coloured, yellowish-grey spots surrounding the centre. Under

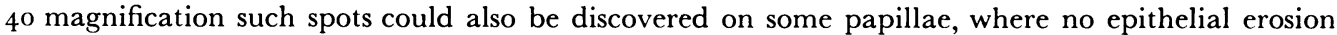
had occurred. 
Almost the entire corneal surface showed more or less widely dispersed round, whitish, flat maculae as well as linear scratches. The spots were either isolated or merged into irregular patterns.

The epithelial erosions usually extended to Bowman's membrane. At 25 magnification the spots appeared to be granular. After 3 to 5 days the epithelial erosions healed in some parts of the conjunctiva. In the corneae the areas of superficial infiltration were by now confined to the periphery.

On the $5^{\text {th }}, 6$ th, and 7 th days the oedema was rapidly disappearing. Ecchymoses were still scattered over almost the entire bulbar conjunctiva, but vasodilatation was receding. The papillae, the epithelial erosions, and the yellowish spots round their apices had mostly disappeared.

The keratitis showed a marked improvement. Between the 8th and 1 oth day the keratitis had almost entirely cleared. A few sparse papillae still showed, but they had disappeared together with the ecchymoses of the bulbar conjunctiva by about the 2 oth day.

\section{INDIREGT CONTAGT}

Case 2, a man aged 35, was out shooting among pine trees, when he accidentally received the contents of some pollen-sacs from a distance of about 8 in. into his right eye. He was seen ro hours later, when the symptoms were only about half as intense as in Case $\mathrm{r}$.

Cases 3 to 9. The pollen reached the eye(s), from a distance of $i$ to 3 yards or more, and the symptoms were correspondingly milder and more superficial.

Such cases often do not come under ophthalmological observation and treatment as the symptoms clear spontaneously. Treatment consists mainly in the administration of antihistamines and antiallergics.

\section{Discussion}

The possibility that the above-mentioned epithelial erosions of the conjunctiva and cornea, as well as the colour of the spots at the apices of the papillae at the sites of epithelial erosion, might be due to mechanical abrasion by the pollen-hairs was ruled out because these hairs when considerably enlarged appear to be only about $\mathrm{I} \cdot 5 \mathrm{~mm}$. long and are soft and devoid of any barbs or spikes. Moreover, the other parts of the pine-flower, especially the scales, constitute only secondary factors. The pollen is therefore the primary cause of the irritation; the grains contain toxic substances and their action is only to a minor degree, if at all, mechanical. The changes observed must thus be ascribed principally to allergic reactions.

\section{Summary}

The pollen of the male flowers of the pine tree cause papillary inflammation of the conjunctiva with characteristic changes in this membrane and in the cornea.

\section{Reference}

DUKE-ELDER, s. (1965) "System of Ophthalmology", vol. 8, pt. I, p. 438. Kimpton, London

\section{Additional bibliography}

Boussiou, s. (1968) “Applied Forestry" (in Greek), vol. I. Athens

MILIARAKIs, s. (1922) "Botany" (in Greek), p. 453. Athens 